Centers for Disease Control and Prevention

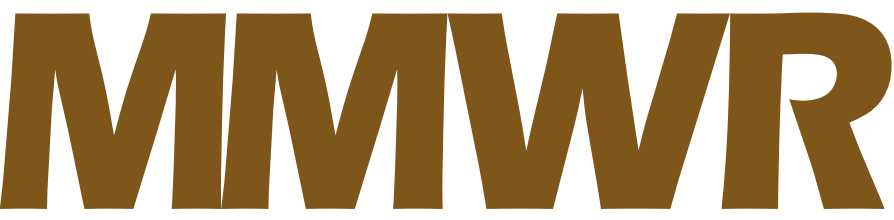

Morbidity and Mortality Weekly Report

Surveillance Summaries / Vol. 66 / No. 2

\title{
Reducing Potentially Excess Deaths from the Five Leading Causes of Death in the Rural United States
}

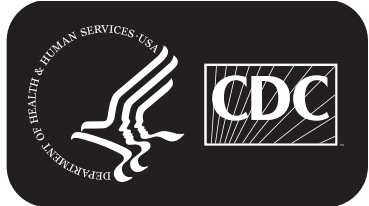


Please note: An erratum has been published for this issue. To view the erratum, please click here.

Surveillance Summaries

\section{CONTENTS}

Background . .1

Reducing Potentially Excess Deaths in

Rural Areas of the United States... 1

Conclusion .5

References. 6

The MMWR series of publications is published by the Center for Surveillance, Epidemiology, and Laboratory Services, Centers for Disease Control and Prevention (CDC), U.S. Department of Health and Human Services, Atlanta, GA 30329-4027.

Suggested citation: [Author names; first three, then et al., if more than six.] [Title]. MMWR Surveill Summ 2017;66(No. SS-\#):[inclusive page numbers].

\section{Centers for Disease Control and Prevention}

Thomas R. Frieden, MD, MPH, Director

Harold W. Jaffe, MD, MA, Associate Director for Science

Joanne Cono, MD, ScM, Director, Office of Science Quality

Chesley L. Richards, MD, MPH, Deputy Director for Public Health Scientific Services

Michael F. Iademarco, MD, MPH, Director, Center for Surveillance, Epidemiology, and Laboratory Services

Sonja A. Rasmussen, MD, MS, Editor-in-Chief

\section{MMWR Editorial and Production Staff (Serials)}

Charlotte K. Kent, $\mathrm{PhD}$, MPH, Executive Editor Christine G. Casey, MD, Editor

Teresa F. Rutledge, Managing Editor

David C. Johnson, Lead Technical Writer-Editor and Project Editor
Martha F. Boyd, Lead Visual Information Specialist

Maureen A. Leahy, Julia C. Martinroe,

Stephen R. Spriggs, Moua Yang, Tong Yang, Visual Information Specialists

Quang M. Doan, MBA, Phyllis H. King, Terraye M. Starr, Information Technology Specialists
Timothy F. Jones, MD, Chairman

Matthew L. Boulton, MD, MPH

Virginia A. Caine, MD

Katherine Lyon Daniel, $\mathrm{PhD}$

Jonathan E. Fielding, MD, MPH, MBA

David W. Fleming, MD
MMWR Editorial Board

William E. Halperin, MD, DrPH, MPH

King K. Holmes, MD, PhD

Robin Ikeda, MD, MPH

Rima F. Khabbaz, MD

Phyllis Meadows, $\mathrm{PhD}, \mathrm{MSN}, \mathrm{RN}$

Jewel Mullen, MD, MPH, MPA
Jeff Niederdeppe, $\mathrm{PhD}$

Patricia Quinlisk, MD, MPH

Patrick L. Remington, MD, MPH Carlos Roig, MS, MA

William L. Roper, MD, MPH

William Schaffner, MD 


\title{
Reducing Potentially Excess Deaths from the Five Leading Causes of Death in the Rural United States
}

\author{
Macarena C. Garcia, DrPH ${ }^{1}$ \\ Mark Faul, $\mathrm{PhD}^{2}$ \\ Greta Massetti, $\mathrm{PhD}^{3}$ \\ Cheryll C. Thomas, $\mathrm{MSPH}^{3}$ \\ Yuling Hong, $\mathrm{MD}^{3}$ \\ Ursula E. Bauer, PhD $^{3}$ \\ Michael F. Iademarco, $\mathrm{MD}^{1}$ \\ ${ }^{1}$ Center for Surveillance, Epidemiology, and Laboratory Services, CDC \\ ${ }^{2}$ National Center for Injury Prevention and Control, CDC \\ ${ }^{3}$ National Center for Chronic Disease Prevention and Health Promotion, CDC
}

\section{Background}

In 2014, the all-cause age-adjusted death rate in the United States reached a historic low of 724.6 per 100,000 population (1). However, mortality in rural (nonmetropolitan) areas of the United States has decreased at a much slower pace, resulting in a widening gap between rural mortality rates (830.5) and urban mortality rates (704.3) (1). During 1999-2014, annual age-adjusted death rates for the five leading causes of death in the United States (heart disease, cancer, unintentional injury, chronic lower respiratory disease [CLRD], and stroke) were higher in rural areas than in urban (metropolitan) areas (Figure 1). In most public health regions (Figure 2), the proportion of deaths among persons aged $<80$ years (U.S. average life expectancy) (2) from the five leading causes that were potentially excess deaths were higher in rural areas compared with urban areas (Figure 3 ). Several factors probably influence the rural-urban gap in potentially excess deaths from the five leading causes, many of which are associated with sociodemographic differences between rural and urban areas. Residents of rural areas in the United States tend to be older, poorer, and sicker than their urban counterparts (3). A higher proportion of the rural U.S. population reports limited physical activity because of chronic conditions than urban populations (4). Moreover, social circumstances and behaviors have an impact on mortality and potentially contribute to approximately half of the determining causes of potentially excess deaths (5).

Potentially excess deaths (also described as potentially preventable deaths) are defined as deaths among persons aged $<80$ years in excess of the number that would be expected if the death rates for each cause were equivalent across all states to those that occurred among the three states with the

Corresponding author: Macarena C. Garcia, DrPH, Center for Surveillance, Epidemiology, and Laboratory Services. Telephone: 404-498-0985; E-mail: kou3@cdc.gov. lowest rates $(6,7)$. Although not all potentially excess deaths can be prevented, many might represent deaths that could be prevented through improved public health programs that support healthier behaviors and neighborhoods and better access to health care services.

\section{Reducing Potentially Excess Deaths in Rural Areas of the United States}

In 2014 , approximately $62 \%$ of all $1,622,304$ deaths in the United States were related to the five leading causes of death (6). During 2014, the number of potentially excess deaths from the five leading causes in rural areas was higher than those in urban areas (8). Targeted, needs-based prevention efforts, combined with improved access to treatment for chronic conditions, might reduce the rural-urban gap in age-adjusted death rates and potentially excess deaths from the five leading causes of death.

\section{Heart Disease, Stroke, and Chronic Lower Respiratory Disease}

Heart disease, stroke, and CLRD share several substantial co-morbidities from individual behavioral and social risk factors (9-12). The percentage of potentially excess deaths from these three causes is higher in rural than urban areas in all 10 regions (8). In addition, potentially excess deaths among regions vary substantially. For example, the percentages of excess deaths in urban areas in regions 3, 4, 5, 6 and 7 related to stroke are higher than even the rural area percentages in regions 1, 2, 8, 9, and 10 . For these three causes of potentially excess deaths, the highest urban percent in one or more regions is higher than the lowest rural percentages in three or more regions. Stroke is the most prominent example: urban excess deaths in regions 4 (South East) and 6 (New Mexico, Texas, Oklahoma, Arkansas, and Louisiana) far outpace rural excess deaths in regions $1,2,5,7,8,9$ and 10 . In region 5 (Great 
FIGURE 1. Age-adjusted death rates among persons of all ages for five leading causes of death in nonmetropolitan and metropolitan areas,* by year — National Vital Statistics System, United States, 1999-2014

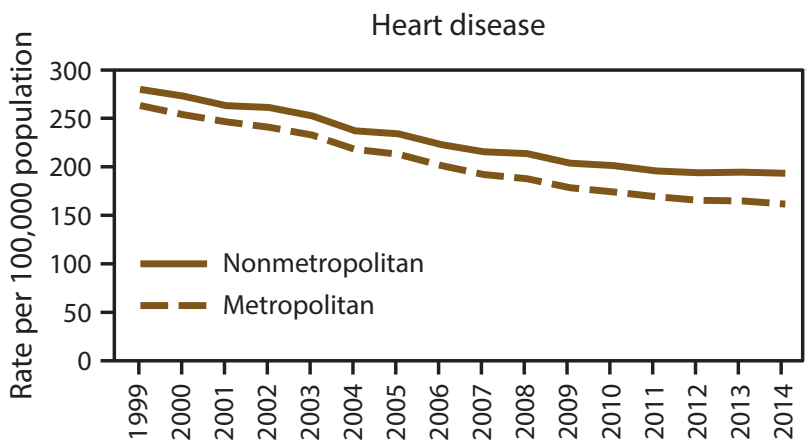

Year

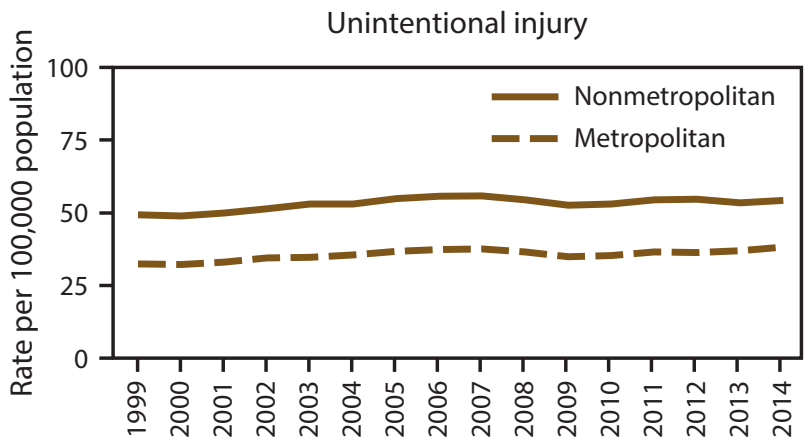

Year

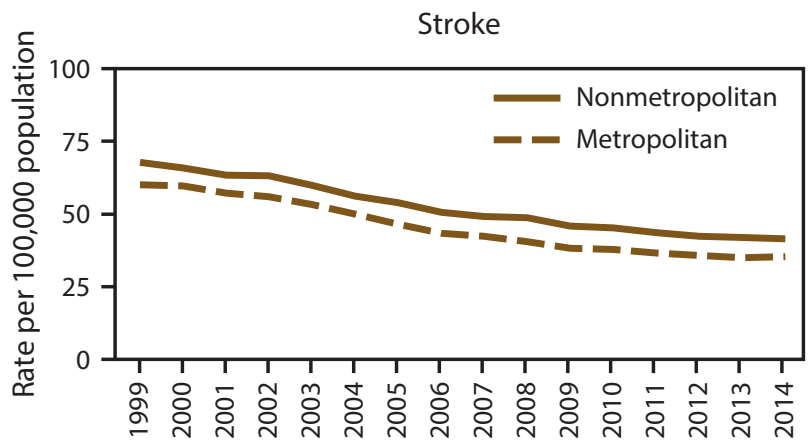

Year

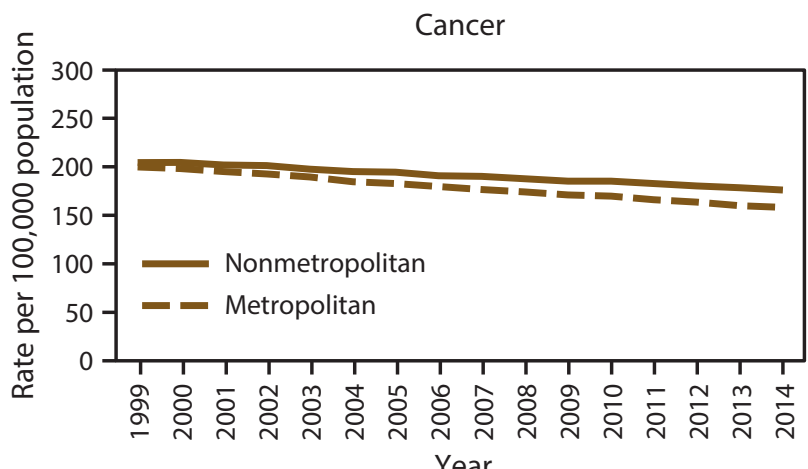

Year

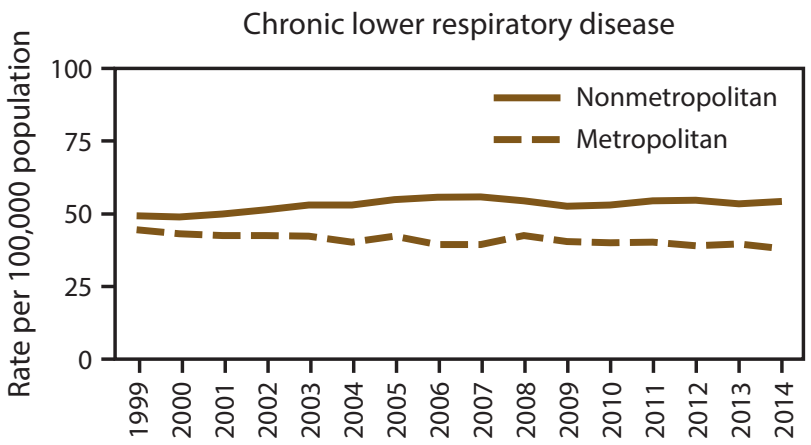

Year

Source: Moy E, García MG, Bastian B, et al. Leading causes of death in nonmetropolitan and metropolitan areas—United States, 1999-2014. MMWR Surveill Summ 2017;66(No. SS-1).

* Nonmetropolitan and metropolitan areas were identified using the Office of Management and Budget's 2013 county-based classification scheme. (Source: Office of Management and Budget, White House. Revised delineations of metropolitan statistical areas, micropolitan statistical areas, and combined statistical areas, and guidance on uses of the delineations of these areas. Washington, DC: Office of Management and Budget; 2013. https://www.whitehouse.gov/sites/default/files/ omb/bulletins/2013/b13-01.pdf)

Lakes), rural-urban differences in potentially excess deaths nearly disappeared for heart disease and stroke. Additional research is needed to understand the causes of these differences and what can be learned from both the broad regional differences across the United States and the near elimination of rural-urban differences in the Great Lakes region.
Tobacco use increases the risk for developing and dying from heart disease, stroke, and CLRD. Cigarette smoking is the leading cause of preventable disease and death in the United States (13) and is the most substantive risk factor for CLRD (10). Nationally, the prevalence of cigarette smoking among adults living in rural counties is higher than in urban counties, and smoking rates differ markedly by region, making tobacco use a likely leading 
FIGURE 2. U.S. Department of Health and Human Services public health regions*

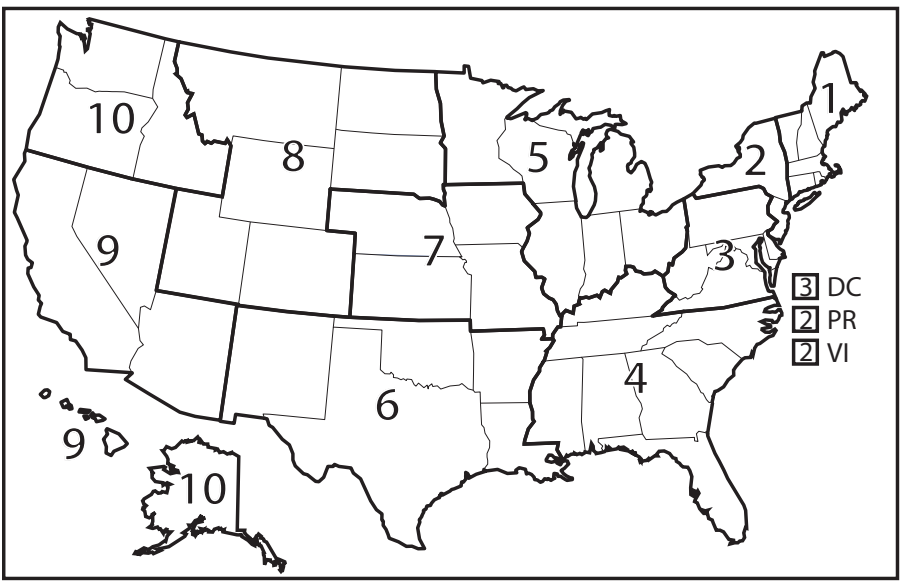

Source: Moy E, García MG, Bastian B, et al. Leading causes of death in nonmetropolitan and metropolitan areas-United States, 1999-2014. MMWR Surveill Summ 2017;66(No. SS-1).

* 1 = Connecticut, Maine, Massachusetts, New Hampshire, Rhode Island, and Vermont; 2 = New Jersey, New York, Puerto Rico, and the U.S. Virgin Islands (Mortality data for residents of U.S. territories were excluded.); $3=$ Delaware, District of Columbia, Maryland, Pennsylvania, Virginia, and West Virginia; 4 = Alabama, Florida, Georgia, Kentucky, Mississippi, North Carolina, South Carolina, and Tennessee; 5 = Illinois, Indiana, Michigan, Minnesota, Ohio, and Wisconsin; 6 = Arkansas, Louisiana, New Mexico, Oklahoma, and Texas; $7=$ lowa, Kansas, Missouri, and Nebraska; $8=$ Colorado, Montana, North Dakota, South Dakota, Utah, and Wyoming; 9 = Arizona, California, Hawaii, and Nevada; $10=$ Alaska, Idaho, Oregon, and Washington.

cause of differential mortality between urban and rural areas (4). Understanding where tobacco use in rural areas is higher than urban areas can help prioritize resources to reduce tobacco use and secondhand smoke exposure and begin to address the increasing numbers of CLRD-related deaths in rural areas.

Heart disease and stroke mortality rates are decreasing in both rural and urban areas. However, this improvement in mortality trends is plateauing and the rate of decline for heart disease in rural areas is slowing relative to urban areas, thus increasing the differential rural-urban gap in mortality rates (8). In 22 states, including rural states such as Alaska, Idaho, Kentucky, Montana, Vermont and West Virginia, the number of deaths attributed to heart disease declined below the number of cancer deaths for the first time (8). For stroke, the difference in the number of deaths in rural and urban areas remained constant, with substantive declines in both rural and urban areas (8). In 2013, stroke declined from the third to the fifth leading cause of death in nonmetropolitan areas (14). Lack of physical activity, poor nutrition (especially diets high in calories, sodium, added sugars, and saturated fat), and associated obesity are major risk factors for hypertension and diabetes (15). These risk factors and conditions contribute substantially to heart disease and stroke death rates in the United States and are more prevalent in rural areas than urban areas. Obesity has been linked to a variety of serious chronic illnesses, including diabetes, heart disease, cancer, and arthritis (16-18). From 1960 to 2010, the proportion of adults in the United States who were overweight or obese increased from $40.5 \%$ to $66.1 \%$ (19). Self-reported obesity was higher in rural areas than urban areas and increased with increasing levels of rurality (4). Regular physical activity and improved physical fitness offer numerous health benefits, including reduced risk for cardiovascular disease, diabetes, obesity, some cancers, and musculoskeletal conditions (20). Despite evidence of modest increases in the prevalence of physical activity and improved nutrition, the prevalence rates of hypertension and diabetes have not been improving over time $(21,22)$. However, a greater percentage of adults with hypertension are controlling their blood pressure (23), and since 2006 there has been a sustained decline in the incidence of diabetes and a plateauing in the prevalence of diabetes nationally (24).

Barriers to health care access result in unmet health care needs that include, but are not limited to, a lack of preventive and screening services, treatment of illnesses (25) and timely urgent and emergency services (26). Residents of rural areas experience many of these barriers. Specifically, rural counties in the United States have a higher uninsured rate (27); experience health care workforce shortages (approximately only 11 percent of all physicians choose to practice in rural settings) (28); often lack subspecialty care (e.g., oncology), critical care units, or emergency facilities (29); have limited transportation options; and experience longer time to services caused by distance (26). Differential access to quality health care (25), including timely access, likely contributes to rural-urban gaps in mortality rates and potentially excess deaths. For example, persons with CLRD and unmet health care needs in rural areas can experience serious life-threatening respiratory episodes, and the lack of timely access to emergency care could affect survival. In contrast, the parallel mortality trends for stroke might be explained by the success of complementary programs that improve the quality of stroke care. These programs (CDC's Paul Coverdell National Acute Stroke Program, the American Heart Association/American Stroke Association's Get with the Guidelines program, and The Joint Commission's Certification for Primary Stroke Centers program) organize systems that coordinate acute stroke care across both urban and rural hospitals (30). However, comparable programs to improve cardiac care have not been implemented in rural areas, which might account for divergent trend in myocardial infarction mortality rates.

\section{Cancer}

During 2003-2012, the overall cancer-related age-adjusted death rate decreased by $1.5 \%$ per year (31); however, rates 
FIGURE 3. Percentage of potentially excess deaths* among persons aged $<80$ years for five leading causes of death in nonmetropolitan and metropolitan areas, ${ }^{\dagger}$ by year and public health region ${ }^{\S}$ - National Vital Statistics System, United States, 2014
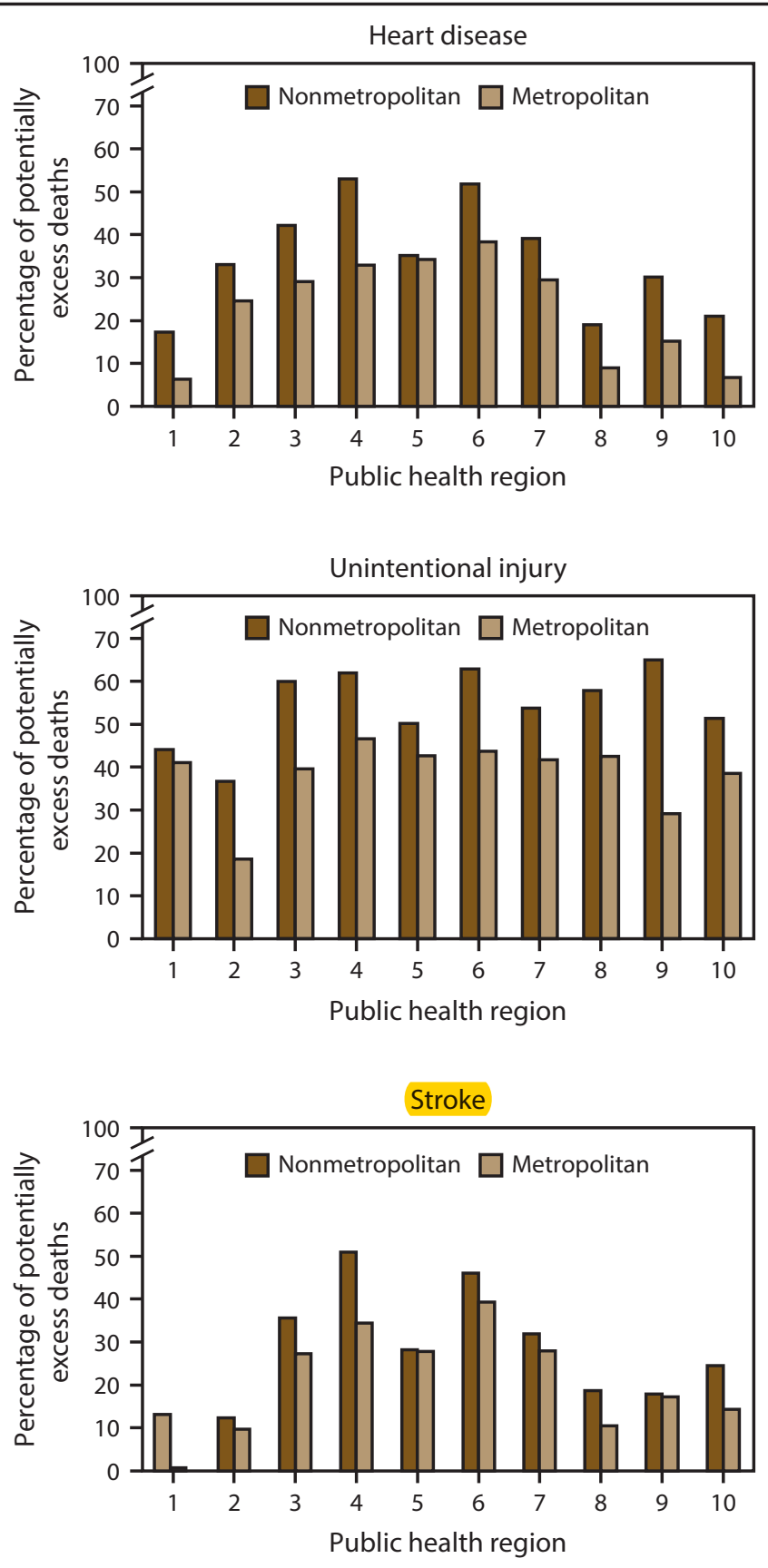
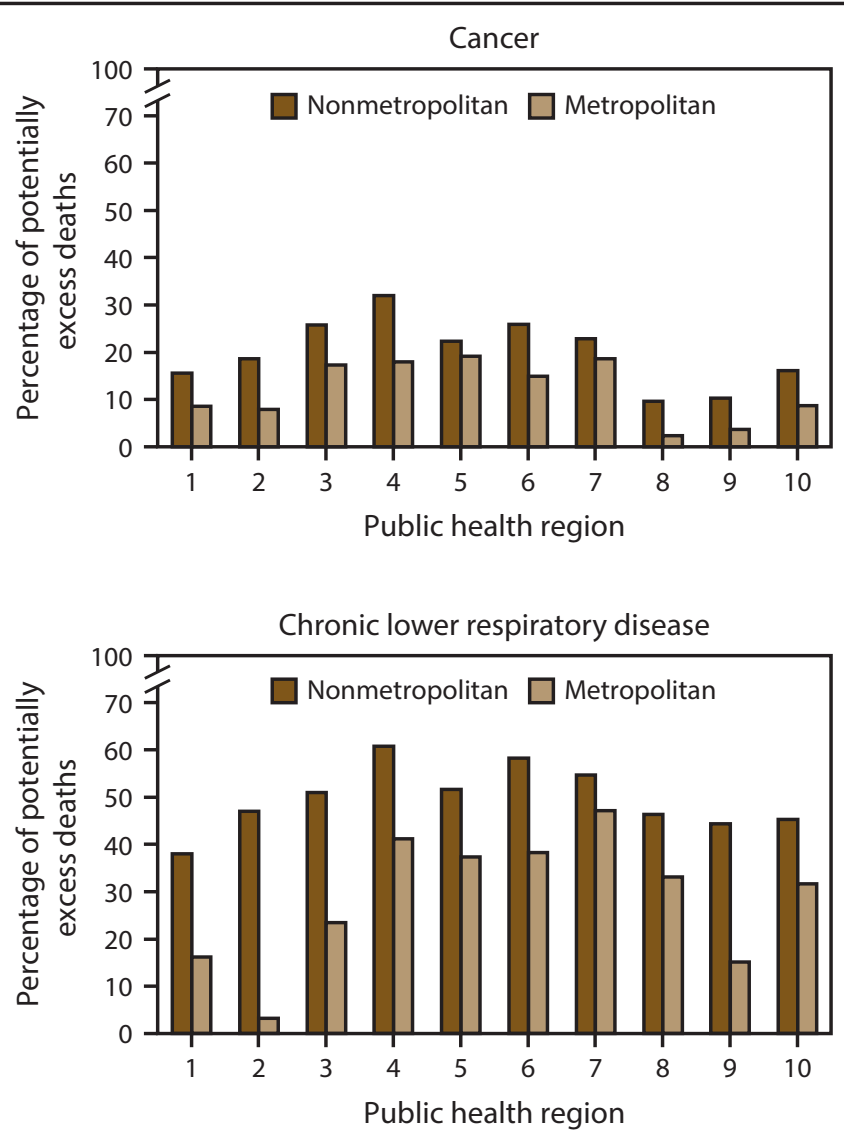

Source: Moy E, García MG, Bastian B, et al. Leading causes of death in nonmetropolitan and metropolitan areas—United States, 1999-2014. MMWR Surveill Summ 2017;66(No. SS-1).

* For each age group and cause, the death rates of the three states with the lowest rates during 2008-2010 (benchmark states) were averaged to produce benchmark rates. Potentially excess deaths were defined as deaths among persons aged $<80$ years in excess of the number that would be expected if the age group-specific death rates of the benchmark states occurred across all states.

† Nonmetropolitan and metropolitan areas were identified using the Office of Management and Budget's 2013 county-based classification scheme. (Source: Office of Management and Budget, White House. Revised delineations of metropolitan statistical areas, micropolitan statistical areas, and combined statistical areas, and guidance on uses of the delineations of these areas. Washington, DC: Office of Management and Budget; 2013. https://www.whitehouse.gov/sites/default/files/ omb/bulletins/2013/b13-01.pdf).

$\S 1$ = Connecticut, Maine, Massachusetts, New Hampshire, Rhode Island, and Vermont; 2 = New Jersey and New York; $3=$ Delaware, District of Columbia, Maryland, Pennsylvania, Virginia, and West Virginia; 4 = Alabama, Florida, Georgia, Kentucky, Mississippi, North Carolina, South Carolina, and Tennessee; $5=$ Illinois, Indiana, Michigan, Minnesota, Ohio, and Wisconsin; $6=$ Arkansas, Louisiana, New Mexico, Oklahoma, and Texas; $7=$ lowa, Kansas, Missouri, and Nebraska; $8=$ Colorado, Montana, North Dakota, South Dakota, Utah, and Wyoming; 9 = Arizona, California, Hawaii, and Nevada; 10 = Alaska, Idaho, Oregon, and Washington. 
declined less in rural than urban areas (8). Age-adjusted death rates from cancer have mirrored decreases in the prevalence of risk factors such as tobacco use, which is a shared risk factor with heart disease, stroke, and CLRD (10-12), and increases in cancer screening, vaccinations, and improvements in treatment (31). Differences in these death rates might reflect higher prevalence of tobacco-use and obesity in rural areas (4) and lack of access to cancer screening services, follow-up to abnormal tests, quality care for cancer patients, and cancer survival care (32).

To address the rural-urban gap in cancer-related potentially excess deaths, comprehensive approaches that encompass the cancer continuum (e.g., prevention, early detection, treatment, and survivorship) are needed at the local and state level to reduce risks associated with potentially excess deaths from cancer in rural areas (33). Comprehensive cancer-control programs are funded by CDC in 50 states, the District of Columbia, seven tribes and tribal organizations, and seven U.S. territories and Pacific Island jurisdictions (https://www. cdc.gov/cancer/ncccp/about.htm). These programs build coalitions that develop and implement strategic plans for cancer prevention and reduce morbidity and mortality for persons affected by cancer.

CDC also supports cancer screening programs that address health disparities among adults who are uninsured or underinsured $(34,35)$, which is a common characteristic among rural populations (32). Historically, funding for the National Breast and Cervical Cancer Early Detection Program and the Colorectal Cancer Control Program has focused on direct screening services. Since 2012, emphasis has shifted to population-based approaches, such as partnering with health systems to implement evidence-based interventions to increase population-level screening (36), including provider reminders for persons who are due for cancer screening (37).

As differences in cancer-related death rates are addressed at the local and state level, opportunities are available to address them at the federal level. The Cancer Moonshot is focused on accelerating the understanding of cancer and its prevention, early detection, treatment, and cure, including improving access and care (38). Although some components of this federal initiative target the genomic level, when combined with population-based approaches, the rural-urban gap in cancer-related deaths rates might be reduced.

\section{Unintentional Injury}

During 2008-2010, the annual age-adjusted death rates for unintentional injury were highest in rural counties (8). During 1999-2014, the age-adjusted death rates for unintentional injuries were approximately $50 \%$ higher in rural areas than urban areas (Figure 1). Several factors explain the wide gap in rural-urban death rates from unintentional injuries. First, unintentional injury burden is higher in rural areas because of severe trauma associated with high speed motor vehicle trafficrelated deaths (4). Second, rates of opioid analgesic misuse and overdose death are highest among poor and rural populations (39). Third, behavioral factors (e.g., alcohol impaired driving, seatbelt use, and opioid prescribing) contribute to higher injury rates in rural areas (40-42). Fourth, access to treatment for trauma and drug poisoning is often delayed when the injury occurs in rural areas. For life-threatening injury, higher survival is associated with rapid emergency treatment $(43,44)$. Because of the geographic distance involved, emergency medical service (EMS) providers who operate ambulances take longer to reach injured or poisoned patients in rural areas. Moreover, ambulatory transport to the optimal treatment facility also can take longer because of increased distance to the treatment facility. Most life threatening trauma is best treated in advanced trauma centers, which are usually located in urban areas; care at these centers has been associated with $25 \%$ lower mortality (45). Trauma centers have advanced equipment and specialized staff available 24 hours, 7 days a week. Such care also includes access to advanced neurosurgical care, which is important because approximately one third of all injury-related deaths involve a traumatic brain injury. Regulatory restrictions and EMS capability and certification to treat drug overdose cases with naloxone at the scene of overdose events also might be a factor in higher opioid poisoning-related deaths in rural areas. Interventions to address the disproportionate unintentional injury death rates in rural areas include increased adherence to guidelines for triaging ambulatory transport destinations (46), changing state rules to expand the types of EMS providers that can administer naloxone to reverse a drug overdose (47), and enforcement of motor vehicle seatbelt and alcohol laws to reduce motor vehicle crashes (48). Educating rural opioid prescribers on the opioid guideline (49) and better access to opioid agonist medication-assisted treatment programs probably would benefit rural communities with high opioid use disorder rates (50). Quicker access to definitive trauma and opioid dependency treatment and additional interventions are needed to reduce unintentional injury deaths in rural areas.

\section{Conclusion}

In the United States, there is a rural-urban gap in ageadjusted death rates and potentially excess deaths from the five leading causes of death. Rural communities experience higher age-adjusted death rates and a higher number of potentially excess deaths from the five leading causes compared with urban 
areas. Higher death rates and potentially excess deaths are often associated with various societal, geographic, behavioral, and structural factors. Historic trends indicate that focusing on access to health care in rural areas of the United States alone is not sufficient to adequately address complex health outcomes, including mortality among rural populations (3). Consistent with the recommendations and best practices described in this report, approaches to address the nonuniform achievements in rural areas must focus on strengthening the health care delivery system while improving and increasing the integration of primary, specialty, and substance abuse services (3). Identifying structural and societal modifiable factors contributing to the gap between rural and urban mortality outcomes from the five leading causes of death is challenging. Additional analysis can yield results that inform the strategic alignment of resources with condition-specific needs. To reverse the widening gap in age-adjusted death rates from unintentional injuries between rural and urban areas, special attention should be given to designing, implementing, and monitoring locally informed initiatives in rural communities for the effective prevention and treatment of opioid misuse, including treatment of opioid overdose. Needs-based allocation of resources can substantially impact rural health. Although rural communities are at higher risk for death from the five leading causes of death, funding to address risk factors is allocated on a population basis (3), often resulting in underfunded rural programs. An increased emphasis on need and epidemiologic burden of disease as major factors in targeting future allocation of public health and prevention funding might contribute, among other factors, to bridging the mortality gap from the five leading causes of death between rural and urban areas in the United States.

\section{Acknowledgments}

Debra Houry, MD, National Center for Injury Prevention and Control; Mary G. George, MD, National Center for Chronic Disease Prevention and Health Promotion.

\section{References}

1. Kochanek KD, Murphy SL, Xu JQ, Tejada-Vera B. Deaths: Final data for 2014. Natl Vital Stat Rep 2016;65(4).

2. Arias E. United States life tables, 2010. Natl Vital Stat Rep 2014;63:1-63.

3. Health Resources and Services Administration. Mortality and life expectancy in rural America: Connecting the health and human service safety nets to improve health outcomes over the life course. Rockville, MD: U.S. Department of Health and Human Services, Health Resources and Services Administration; 2015. https://www.hrsa.gov/ advisorycommittees/rural/publications/mortality.pdf

4. Meit M, Knudson A, Gilbert T, et al. The 2014 update of the Rural-Urban Chartbook. Grand Forks, ND: Rural Health Reform Policy Research Center; 2014. https://ruralhealth.und.edu/projects/health-reform-policyresearch-center/pdf/2014-rural-urban-chartbook-update.pdf
5. Booske BC, Athen JK, Kindig DA, et al. County health rankings working paper: Different perspectives for assigning weights to determinants of health. Madison, WI: University of Wisconsin, Population Health Institute; 2010. https://uwphi.pophealth.wisc.edu/publications/other/different-perspectivesfor-assigning-weights-to-determinants-of-health.pdf

6. Yoon PW, Bastian B, Anderson RN, Collins JL, Jaffe HW. Potentially preventable deaths from the five leading causes of death-United States, 2008-2010. MMWR Morb Mortal Wkly Rep 2014;63:369-74.

7. García MC, Bastian B, Rossen LM, et al. Potentially preventable deaths among the five leading causes of death-United States, 2010 and 2014. MMWR Morb Mortal Wkly Rep 2016;65:1245-55. http://dx.doi. org/10.15585/mmwr.mm6545a1

8. Moy E, García MG, Bastian B, et al. Leading causes of death in nonmetropolitan and metropolitan areas-United States, 1999-2014. MMWR Surveill Summ 2017;66(No. SS-1).

9. Bauer UE, Briss PA, Goodman RA, Bowman BA. Prevention of chronic disease in the 21 st century: elimination of the leading preventable causes of premature death and disability in the USA. Lancet 2014;384:45-52. http://dx.doi.org/10.1016/S0140-6736(14)60648-6

10. US Department of Health and Human Services. The health consequences of smoking: 50 years of progress. A report of the Surgeon General. Atlanta, GA: US Department of Health and Human Services, CDC; 2014.

11. Havranek EP, Mujahid MS, Barr DA, et al.; American Heart Association Council on Quality of Care and Outcomes Research, Council on Epidemiology and Prevention, Council on Cardiovascular and Stroke Nursing, Council on Lifestyle and Cardiometabolic Health, and Stroke Council. Social determinants of risk and outcomes for cardiovascular disease: A scientific statement From the American Heart Association. Circulation 2015;132:873-98. http://dx.doi.org/10.1161/CIR.0000000000000228

12. Celedón JC, Roman J, Schraufnagel DE, Thomas A, Samet J; The American Thoracic Society Perspective. Respiratory health equality in the United States. The American Thoracic Society perspective. Ann Am Thorac Soc 2014;11:473-9. http://dx.doi.org/10.1513/AnnalsATS.201402-059PS

13. US Department of Health and Human Services. Tobacco use. Healthy people 2020. Washington, DC: U.S. Department of Health and Human Services; 2013. https://www.healthypeople.gov/2020/topics-objectives/ topic/tobacco-use?topicid $=41$

14. Heron M. Deaths: Leading causes of death for 2011. Natl Vital Stat Rep 2015;64:1-96.

15. US Department of Health and Human Services. Nutrition and weight status. Healthy people 2020. Washington, DC: US Department of Health and Human Services; 2013. https://www.healthypeople. gov/2020/topics-objectives/topic/nutrition-and-weight-status

16. Wang J, Yang DL, Chen ZZ, Gou BF. Associations of body mass index with cancer incidence among populations, genders, and menopausal status: A systematic review and meta-analysis. Cancer Epidemiol 2016;42:1-8. http://dx.doi.org/10.1016/j.canep.2016.02.010

17. National Institutes of Health. Managing overweight and obesity in adults: systematic evidence review from the Obesity Expert Panel, 2013. Rockville, MD; US Department of Health and Human Services, National Institutes of Health; 2013.

18. Bliddal H, Leeds AR, Christensen R. Osteoarthritis, obesity and weight loss: evidence, hypotheses and horizons-a scoping review. Obes Rev 2014;15:578-86. http://dx.doi.org/10.1111/obr.12173

19. CDC. Prevalence of overweight, obesity, and extreme obesity among adults: United States, 1960-1962 through 2011-2012; 2014. https://www.cdc. gov/nchs/data/hestat/obesity_adult_11_12/obesity_adult_11_12.htm

20. CDC. Physical activity and health: the benefits of physical activity. Atlanta, GA: US Department of Health and Human Services, CDC; 2011. https://www.cdc.gov/physicalactivity/everyone/health/index.html.

21. Rehm CD, Peñalvo JL, Afshin A, Mozaffarian D. Dietary intake among U.S. adults, 1999-2012. JAMA 2016;315:2542-53. http://dx.doi. org/10.1001/jama.2016.7491 
22. U.S. Department of Health and Human Services. Health, United States, 2015: with special feature on racial and ethnic health disparities. Hyattsville, MD: U.S. Department of Health and Human Services, National Center for Health Statistics; 2016. https://www.cdc.gov/nchs/ data/hus/hus15.pdf

23. Yoon SS, Fryar CD, Carroll MD. Hypertension prevalence and control among adults: United States, 2011-2014. NCHS data brief, no 220. Hyattsville, MD: US Department of Health and Human Services, National Center for Health Statistics; 2015.

24. CDC. Crude and age-adjusted incidence of diagnosed diabetes per 1,000 population aged 18-79 years, United States, 1980-2014. Atlanta, GA: US Department of Health and Human Services, CDC; 2015. https:// www.cdc.gov/diabetes/statistics/incidence/fig2.htm

25. A. Clinton MacKinney AC. Access to rural health care-a literature review and new synthesis. Iowa City, IA: Rural Policy Research Institute; 2014. http://www.rupri.org/Forms/HealthPanel_Access_August2014.pdf

26. Payne S, Jarrett N, Jeffs D. The impact of travel on cancer patients' experiences of treatment: a literature review. Eur J Cancer Care (Engl) 2000;9:197-203. http://dx.doi.org/10.1046/j.1365-2354.2000.00225.x

27. US Department of Health and Human Services. Health, United States, 2013: with special feature on prescription drugs. Hyattsville, MD: US Department of Health and Human Services, National Center for Health Statistics; 2014.

28. Cromartie J. Population and migration. Washington, DC: US Department of Agriculture, Economic Research Service; 2012. https://www.ers.usda. gov/topics/rural-economy-population/population-migration.aspx

29. Gamm LD, Hutchinson LL, Dabney BJ, Dorsey AM. Rural healthy people 2010: a companion document to healthy people 2010, volume 1 . College Station, TX: The Texas A\&M University System Health Science Center, School of Rural Public Health, Southwest Rural Health Research Center; 2003.

30. Gorelick PB. Primary and comprehensive stroke centers: history, value and certification criteria. J Stroke 2013;15:78-89. http://dx.doi. org/10.5853/jos.2013.15.2.78

31. Ryerson AB, Eheman CR, Altekruse SF, et al. Annual report to the nation on the status of cancer, 1975-2012, featuring the increasing incidence of liver cancer. Cancer 2016;122:1312-37. http://dx.doi.org/10.1002/cncr.29936

32. Meilleur A, Subramanian SV, Plascak JJ, Fisher JL, Paskett ED, Lamont EB. Rural residence and cancer outcomes in the United States: issues and challenges. Cancer Epidemiol Biomarkers Prev 2013;22:1657-67. http://dx.doi.org/10.1158/1055-9965.EPI-13-0404

33. US Department of Health and Human Services. Cancer control continuum. Washington, DC: US Department of Health and Human Services, National Cancer Institute; 2015. https://cancercontrol.cancer. gov/OD/continuum.html

34. CDC. National Breast and Cervical Cancer Early Detection Program: about the program. Atlanta, GA: US Department of Health and Human Services, CDC; 2016. https://www.cdc.gov/cancer/nbccedp/about.htm

35. CDC. Colorectal Cancer Control Program. Atlanta, GA: US Department of Health and Human Services, CDC; 2016. https://www.cdc.gov/ cancer/crccp/index.htm
36. CDC. The Community Guide: Cancer. Atlanta, GA: US Department of Health and Human Services, CDC; 2015. https://www. thecommunityguide.org/topic/cancer

37. Plescia M, Richardson LC, Joseph D. New roles for public health in cancer screening. CA Cancer J Clin 2012;62:217-9. http://dx.doi. org $/ 10.3322 /$ caac. 21147

38. Office of the President. Cancer moonshot. Washington, DC: Office of the President; 2015. https://www.whitehouse.gov/CancerMoonshot.

39. CDC. CDC grand rounds: prescription drug overdoses-a U.S. epidemic. MMWR Morb Mortal Wkly Rep 2012;61:10-3.

40. Borgialli DA, Hill EM, Maio RF, Compton CP, Gregor MA. Effects of alcohol on the geographic variation of driver fatalities in motor vehicle crashes. Acad Emerg Med 2000;7:7-13. http://dx.doi. org/10.1111/j.1553-2712.2000.tb01882.x

41. Strine TW, Beck LF, Bolen J, Okoro C, Dhingra S, Balluz L. Geographic and sociodemographic variation in self-reported seat belt use in the United States. Accid Anal Prev 2010;42:1066-71. http://dx.doi. org/10.1016/j.aap.2009.12.014

42. Pletcher MJ, Kertesz SG, Kohn MA, Gonzales R. Trends in opioid prescribing by race/ethnicity for patients seeking care in U.S. emergency departments. JAMA 2008;299:70-8. http://dx.doi.org/10.1001/jama.2007.64

43. Gonzalez RP, Cummings G, Mulekar M, Rodning CB. Increased mortality in rural vehicular trauma: identifying contributing factors through data linkage. J Trauma 2006;61:404-9. http://dx.doi. org/10.1097/01.ta.0000229816.16305.94

44. Davis CS, Ruiz S, Glynn P, Picariello G, Walley AY. Expanded access to naloxone among firefighters, police officers, and emergency medical technicians in Massachusetts. Am J Public Health 2014;104:e7-9. http:// dx.doi.org/10.2105/AJPH.2014.302062

45. MacKenzie EJ, Rivara FP, Jurkovich GJ, et al. A national evaluation of the effect of trauma-center care on mortality. N Engl J Med 2006;354:366-78. http://dx.doi.org/10.1056/NEJMsa052049

46. Sasser SM, Hunt RC, Faul M, et al. Guidelines for field triage of injured patients: recommendations of the National Expert Panel on Field Triage, 2011. MMWR Recomm Rep 2012;61(No. RR-1).

47. Davis CS, Southwell JK, Niehaus VR, Walley AY, Dailey MW. Emergency medical services naloxone access: a national systematic legal review. Acad Emerg Med 2014;21:1173-7. http://dx.doi.org/10.1111/acem.12485

48. Rakauskas ME, Ward NJ, Gerberich SG. Identification of differences between rural and urban safety cultures. Accid Anal Prev 2009;41:931-7. http://dx.doi.org/10.1016/j.aap.2009.05.008

49. Dowell D, Haegerich TM, Chou R. CDC guideline for prescribing opioids for chronic pain-United States, 2016. MMWR Recomm Rep 2016;65(No. RR-1). http://dx.doi.org/10.15585/mmwr.rr6501e1

50. Jones CM, Campopiano M, Baldwin G, McCance-Katz E. National and state treatment need and capacity for opioid agonist medicationassisted treatment. Am J Public Health 2015;105:e55-63. http://dx.doi. org/10.2105/AJPH.2015.302664 


The Morbidity and Mortality Weekly Report (MMWR) Series is prepared by the Centers for Disease Control and Prevention (CDC) and is available free of charge in electronic format. To receive an electronic copy each week, visit MMWR's free subscription page at http://www.cdc.gov/mmwr/mmwrsubscribe.html. Paper copy subscriptions are available through the Superintendent of Documents, U.S. Government Printing Office, Washington, DC 20402; telephone 202-512-1800.

Readers who have difficulty accessing this PDF file may access the HTML file at http://www.cdc.gov/mmwr/volumes/66/ss/ss6602a1.htm?s_cid=ss6602a1_w. Address all inquiries about the $M M W R$ Series, including material to be considered for publication, to Executive Editor, MMWR Series, Mailstop E-90, CDC, 1600 Clifton Rd., N.E., Atlanta, GA 30329-4027 or to mmwrq@cdc.gov.

All material in the MMWR Series is in the public domain and may be used and reprinted without permission; citation as to source, however, is appreciated.

Use of trade names and commercial sources is for identification only and does not imply endorsement by the U.S. Department of Health and Human Services.

References to non-CDC sites on the Internet are provided as a service to $M M W R$ readers and do not constitute or imply endorsement of these organizations or their programs by CDC or the U.S. Department of Health and Human Services. CDC is not responsible for the content of these sites. URL addresses listed in $M M W R$ were current as of the date of publication.

ISSN: 1546-0738 (Print) 